\section{Distribuição espacial e crescimento da população idosa nas capitais brasileiras de 1980 a 2006: um estudo ecológico}

\author{
Silvana Lopes Nogueira* \\ Júnia Maria Geraldo** \\ Juliana Costa Machado*** \\ Rita de Cássia Lanes Ribeiro ${ }^{\star * * *}$
}

\section{Introdução}

Do ponto de vista demográfico, enveIhecimento é caracterizado pelo aumento na proporção da população a partir de 60 anos, para países em desenvolvimento, e de 65 anos, para os desenvolvidos, em relação à população total. Esse processo ocorre como conseqüência da queda da fecundidade, aliada ao aumento da expectativa de vida e à redução da mortalidade (MOREIRA, 2000; CARVALHO; GARCIA, 2003).

No Brasil, verifica-se que atualmente a redução da natalidade ocorre em ritmo mais acelerado do que a diminuição da mortalidade, resultando em limitação progressiva no ritmo de crescimento populacional (WONG; CARVALHO, 2006).

Segundo a Organização das Nações Unidas (ONU), os idosos representavam, em $2005,10,4 \%$ da população mundial, e projeções revelam que, até 2050, esse valor será superior a $20 \%$. Paralelamente, o percentual de crianças reduzirá de $30 \%$ para $21 \%$, no mesmo período.

Em relação à população brasileira, o grupo de 0 a 14 anos correspondia, em 2000 , a $30 \%$ do total, enquanto os maiores de 65 anos eram apenas 5\%. No entanto, projeções indicam que, em 2050 , os dois grupos se igualarão em 18\% (IBGE, 2007).
A transição demográfica que ocorreu lentamente nos países desenvolvidos acompanhou a elevação da qualidade de vida, com inserção das pessoas no mercado de trabalho, oportunidades educacionais favoráveis, bem como boas condições sanitárias, alimentares, ambientais e de moradia (CERQUEIRA; OLIVEIRA, 2002).

No entanto, no Brasil e em outros países em desenvolvimento, esse processo foi rápido e desvinculado de uma política social favorável, sem melhora concomitante na qualidade de vida da população idosa (CARVALHO; GARCIA, 2003). A cada ano, 650 mil novos idosos são incorporados à população, e a maior parte apresenta doenças crônicas não transmissíveis e limitações funcionais (VERAS, 2007).

Cabe ressaltar que o processo de envelhecimento populacional não ocorre de maneira uniforme em todas as regiões brasileiras. Assim, este trabalho teve como objetivo avaliar a distribuição espacial e o crescimento da população acima de 60 anos no Brasil, focalizando as diferenças entre as capitais. Os dados obtidos foram relacionados entre si e com outros encontrados na literatura, permitindo também que se tenha uma visão prospectiva acerca do processo de envelhecimento nessas cidades.

\section{Metodologia}

Realizou-se um estudo ecológico de série temporal, utilizando dados sobre sexo e faixa etária da população idosa e da total, residentes nas capitais brasileiras e no país, no período de 1980 a 2006. Em relação à cidade de Palmas-TO, encontrouse informações disponíveis somente a partir de 1981.

Os dados foram obtidos diretamente do Sistema de Informação do Ministério da Saúde (DATASUS, 2007) e do Instituto Brasileiro de Geografia e Estatística (IBGE, 2007), acessados entre 10 de janeiro e 25 de fevereiro de 2007.

\footnotetext{
* Profissional de Educação Física. Mestranda em Ciência da Nutrição pela Universidade Federal de Viçosa.

** Nutricionista. Mestranda em Ciência da Nutrição pela Universidade Federal de Viçosa.

${ }^{* * *}$ Economista doméstica, graduada pela Universidade Federal de Viçosa.

${ }^{\star * * *}$ Professora associada da Universidade Federal de Viçosa. Doutora em Saúde Pública pela Universidade Federal de Minas Gerais.
} 
Foi considerado idoso o indivíduo com idade igual ou superior a 60 anos (BRASIL, 2003). Entretanto, o cálculo do índice de envelhecimento foi realizado por meio do quociente entre a população com idade superior a 65 anos e aquela com idade inferior a 15 anos. Esse índice permitiu a identificação de alterações na estrutura etária da população ao longo dos anos estudados. Shryock e Siegel (1976) sugerem um índice de envelhecimento inferior a 15\% como sendo indicativo de uma população jovem; entre 15\% e 30\% uma população em nível intermediário; e acima de $30 \%$ poderia ser considerada uma população idosa.

A distribuição espacial e a evolução do número de idosos nas capitais brasileiras foram verificadas por meio do cálculo da proporção de pessoas de 60 anos e mais por capital, no período estudado.

Realizou-se também a comparação do crescimento percentual dos idosos para o total do Brasil, por sexo, entre 1980 e 2006.

\section{Resultados e discussão}

Durante o período analisado, houve aumento de $59,3 \%$ na população total brasileira, enquanto o grupo acima de 60 anos elevou-se em 118,2\%. Na década de 80 , houve desaceleração no ritmo de crescimento populacional brasileiro, provocada pela queda da fecundidade, mais pronunciada no meio rural. Entretanto, de maneira generalizada, pode-se afirmar que o processo de envelhecimento da população brasileira tem sido muito acelerado, particularmente na Região Sudeste. De acordo com dados das Nações Unidas, de 1975 a 2000, outras populações apresentaram incrementos bem menores na proporção de idosos, como as populações da América do Norte $(20,2 \%)$, Europa $(28,9 \%)$ e Ásia $(40,7 \%)$ (UNITED NATIONS, 2005), o que reflete um processo de envelhecimento diferenciado.

O aumento da população idosa, observado quando se contrastam os dados de 1980 e 2007, é um fenômeno que traz consigo uma série de implicações sociais, culturais e epidemiológicas.

Apenas sete capitais, situadas nos Estados do Sul e Sudeste, as regiões mais urbanizadas e industrializadas do país, permaneceram com proporção de idosos acima da média nacional, que era de $6,07 \%$, em 1980, e 8,44\%, em 2006. As cidades do Rio de Janeiro-RJ e Porto Alegre-RS, tanto em 1980 quanto em 2006, ocupavam o primeiro e o segundo lugares, respectivamente, no percentual de idosos da população das capitais brasileiras. Esta diferença, em comparação com o restante do país, pode estar envolvida, entre outros elementos, com a qualidade de vida, situação socioeconômica e escolaridade de seus habitantes (ALBUQUERQUE, 2005; PEREIRA et al., 2003).

É interessante notar que algumas cidades apresentaram aumento mais acentuado no percentual de idosos nesse período. Como relatado anteriormente, vários fatores interferem no envelhecimento populacional dos municípios, tais como redução nas taxas de fecundidade e aumento da expectativa de vida, mas um aspecto muito importante que deve ser analisado refere-se aos movimentos migratórios, especialmente no caso das capitais. Martignoni et al. (2006) destacam que, no Brasil, a mobilidade da população idosa em relação às migrações é bem menor do que para outras faixas etárias.

No período analisado, o aumento mais expressivo na proporção de idosos foi registrado em Brasília (92,5\%), seguida por Goiânia, com crescimento de $74,7 \%$.

Belo Horizonte também obteve elevação bastante significativa da população idosa, da ordem de 70,4\%. De acordo com Zahreddine e Rigotti (2006), a esperança de vida ao nascer do belorizontino tem aumentado, e a cidade apresentou, entre os censos de 1991 e 2000, redução da taxa de fecundidade total, que atualmente está abaixo da taxa de renovação de gerações, que é de 2,1 filhos. Além disso, o saldo migratório tem se mantido negativo em alguns períodos, e grande parte da população que emigra da capital mineira é formada por jovens. Todos esses fatores corroboraram para que, nos últimos anos, houvesse um envelhecimento desta população.

Para o total do Brasil, observa-se notável variação na estrutura etária da população idosa, entre 1980 e 2006. A faixa etária de 60 a 64 anos contém o maior percentual de 
indivíduos em todo o período, representando cerca de $30 \%$ da população idosa. Entretanto, verifica-se crescimento mais expressivo no grupo de indivíduos acima de 75 anos, especialmente aqueles com 80 anos e mais. Isto indica uma alteração na composição interna do grupo etário dos idosos.

A proporção da população "mais idosa" está aumentando em ritmo bastante acelerado. Em 1980, o Brasil possuía cerca de 560 mil idosos com mais de 80 anos; já em 2006, esta parcela da população aumentou para quase dois milhões de habitantes.

A infra-estrutura das cidades brasileiras deve, portanto, ser adequada para atender a essa maior demanda de idosos, pois, além das alterações demográficas, o Brasil também passa pela transição epidemiológica, com alterações relevantes no quadro de morbimortalidade, em que predominam as doenças crônicas não-transmissíveis. Conseqüentemente, é inevitável que os gastos públicos sejam reforçados no tratamento, hospitalização e reabilitação (ALBUQUERQUE, 2005).

Ao se analisar o índice de envelhecimento no Brasil, observou-se que houve aumento de $85,3 \%$ no intervalo estudado, passando de 10,5\% em 1980 para 19,43\% em 2006 . Em 1980, com exceção do Rio de Janeiro e Porto Alegre, todas as capitais, assim como o total do Brasil, poderiam ser consideradas uma população predominantemente jovem (SHRYOCK; SIEGEL, 1976). Em 1985, 1990 e 1995, esse índice continuou se elevando. Somente em 2000 o Brasil atingiu um índice de envelhecimento intermediário, enquanto 14 capitais apresentavam classificação igual ou superior à do país. Segundo o IBGE (2004), a projeção do índice de envelhecimento para 2050 é de 105,6\%.

Além de possuírem expressivo percentual de idosos, ao longo desses 27 anos, as cidades do Rio de Janeiro e Porto Alegre destacaram-se por apresentarem índices de envelhecimento notadamente superiores às demais capitais. A primeira obteve índices cerca de duas vezes maiores que a média nacional no período estudado. Porto Alegre se manteve em segundo lugar. Recife sobressaiu por registrar um aumento bastante significativo, da ordem de $114,3 \%$, no ín- dice de idosos. Por outro lado, as capitais Palmas e Porto Velho foram as que obtiveram menores índices de envelhecimento neste mesmo período.

Em relação ao gênero, entre os dados obtidos para a população brasileira, encontrou-se maior número de mulheres (aproximadamente $51 \%$ ) do que de homens, para todos os anos. De acordo com Pereira et al. (2003), este fenômeno tem ocorrido não apenas no Brasil, mas também em muitos outros países, pois o aumento da expectativa de vida é sempre mais significativo para as mulheres. Os autores associam esse achado a fatores como o menor consumo de álcool e tabaco (associados a várias doenças), melhoria do atendimento médico-obstétrico e menor exposição a riscos, como acidentes e homicídios (PEREIRA et al., 2003).

\section{Considerações finais}

De um modo geral, o Brasil encontra-se num processo de envelhecimento populacional bastante acelerado, que pode ser evidenciado pela evolução do índice de envelhecimento, no período de 1980 a 2006. Há predominância de idosos entre 60 e 64 anos, embora seja a faixa etária acima de 80 anos a que tem mais se elevado, em termos percentuais. As capitais brasileiras experimentam o mesmo processo, mas em diferentes graus.

Assim, outros estudos são imprescindíveis para acompanhar a tendência do envelhecimento populacional no Brasil, pois, mesmo não tendo sido considerada a migração no presente estudo, a constatação do aumento do número de idosos permite o norteamento de políticas públicas intervencionistas, o que influencia positivamente na qualidade de vida dos idosos.

Por outro lado, tendo em vista a grande velocidade com que este processo ocorre, ações concretas devem ser realizadas, tais como a reestruturação da previdência social e uma aplicação prática mais efetiva dos direitos assegurados no Estatuto do Idoso brasileiro. No âmbito acadêmico e técnico, faz-se necessário investir na formação adequada de profissionais, para lidar com esta parcela da população. 


\section{Referências bibliográficas}

ALBUQUERQUE, S. M. R. L. Envelhecimento ativo: desafio do serviço de saúde para a melhoria da qualidade de vida dos idosos. (Tese de doutorado). Universidade de São Paulo. São Paulo, 2005.

BRASIL. Ministério da Saúde. Lei 10.741 de 10 de outubro de 2003. Estatuto do Idoso. Brasília-DF, 2003.

CARVALHO, J. A. M.; GARCIA, R. A. O envelhecimento da população brasileira: um enfoque demográfico. Cad. Saúde Pública, v.19, n.3, p. 725-733, 2003.

CERQUEIRA, A.; OLIVEIRA, N. Programa de apoio a cuidadores: uma ação terapêutica e preventiva na atenção à saúde dos idosos.

Psicol. USP, v.13, n.1, p. 1-11, 2002.

DATASUS. Departamento de Informática do Sistema Único de Saúde. [Banco de dados na internet]. Brasil, Ministério da Saúde. Disponível em: <http://www.datasus.gov. br>. Acesso em: 25 fev. 2007.

IBGE - Instituto Brasileiro de Geografia e Estatística. Projeção da população do Brasil por sexo e idade para o período 1980-2050: revisão 2004. Rio de Janeiro: IBGE - Depis. Disponível em: <http://www. ibge.gov.br>. Acesso em: 18 fev. 2007.

MARTIGNONI, E. M.; CARVANO, L. M.; JANNUZZI, P. M. Força de trabalho e desemprego na Região Metropolitana do Rio de Janeiro nos anos 1990: o efeito dos fatores demográficos. Rev. Bras. Estud. Popul., v.23, n.2, p.287-299, 2006.

MOREIRA, M. M. Envelhecimento da população brasileira: aspectos gerais. In: WONG, L. L. R. (Org.). O envelhecimento da população brasileira e o aumento da longevidade: subsídios para políticas orientadas ao bem-estar do idoso. Belo Horizonte: Cedeplar/UFMG e Abep, 2000, p. 25-56.

PEREIRA, R. S.; CURIONI, C. C.; VERAS, R. Perfil demográfico da população idosa no Brasil e no Rio de Janeiro em 2002. Text. Envelhec., v.1, p. 43-59, 2003.

SHRYOCK, H. S.; SIEGEL, J. S. The methods and materials of demography. In: STOCKWELL, E. G. Studies in population. Condensed Edition. San Diego (CA): Academic Press, 1976.

VERAS, R. Fórum Envelhecimento populacional e as informações de saúde do PNAD: demandas e desafios contemporâneos. Introdução. Cad. Saúde Pública, v.23, n.10, p. 2.463-2.466, 2007.

WONG, L. L. R.; CARVALHO, J. A. O rápido processo de envelhecimento populacional do Brasil: sérios desafios para as políticas públicas. Rev. Bras. Estud. Popul., v.23, n.1, p. 5-26, 2006.

UNITED NATIONS. World population prospects 1950-2050 - the 2004 revision. New York: Department of Social and Economic Affairs - Population Division, 2005.

ZAHREDDINE, D.; RIGOTTI, J. I. R.; CASTRO, J. F. M.; RODRIGUES, R. N.; AMORIM FILHO, O.B. Mapeamento do processo de envelhecimento populacional em Belo Horizonte - 1991 e 2000. (Dissertação de Mestrado). Pontifícia Universidade Católica de Minas Gerais. Belo Horizonte, 2006.

Recebido para publicação em 28/02/2008. Aceito para publicação em 25/04/2008. 